\title{
PENGARUH PENDIDIKAN DAN PENGALAMAN KERJA TERHADAP KINERJA PEGAWAI BIRO PERLENGKAPAN UMUM KANTOR BUPATI SIGI
}

\author{
Oleh: \\ ${ }^{1}$ Muhamad Gulom, ${ }^{2}$ Nanang Qosim \\ ${ }^{3}$ Muhammad Yasin, ${ }^{4}$ Eva Warta \\ (Dosen Fakultas Ekonomi Universitas Alkhairaat Palu)
}

\begin{abstract}
ABSTRAK
Pegawai yang saat ini mengabdikan dirinya untuk memberikan pelayanan terbaik kepada masyarakat, adalah pegawai yang direkrut dengan melewati sejumlah prosedur dan dianggap memenuhi persyaratan, salah satunya adalah kemampuan. Dalam beberapa teori dinyatakan bahwa semakin baik seseorang, semakin tinggi pula penguasaannya terhadap suatu pekerjaan (Gibson, 1994; 121). Dalam berbagai kajian mengenai sumber daya manusia, posisi kerja sangat ditekankan, khususnya menyangkut kualitas sumber daya manusia. Tujuan penelitian ini adalah untuk mengetahui pengaruh pendidikan dan pengalaman kerja secara serempak terhadap kinerja pegawai Biro Perlengkapan Umum Kantor Bupati Sigi. Jumlah pegawai yang dijadikan sampel sebanyak 36 orang. Alat analisis yang digunakan untuk menjawab hipotesis adalah regresi linier berganda. Hasil penelitian ini menunjukkan bahwa kedua variabel bebas memiliki pengaruh signifikan terhadap kinerja pegawai Biro Perlengkapan Umum Kantor Bupati Sigi. Dengan demikian maka kesimpulan penelitian ini adalah hipotesis pertama sampai hipotesis keempat secara statistic terbukti kebenarannya.
\end{abstract}

\section{Kata Kunci: Pendidikan, Pengalaman Kerja dan Kinerja}

LATAR BELAKANG

Pegawai yang saat ini mengabdikan dirinya untuk memberikan pelayanan terbaik kepada masyarakat, adalah pegawai yang direkrut dengan melewati sejumlah prosedur dan dianggap memenuhi persyaratan, salah satunya adalah kemampuan. Dalam beberapa teori dinyatakan bahwa semakin baik seseorang, semakin tinggi pula penguasaannya terhadap suatu pekerjaan (Gibson, 1994; 121). Dalam berbagai kajian mengenai sumber daya manusia, posisi kerja sangat ditekankan, khususnya menyangkut kualitas sumber daya manusia.
Dengan adanya kualitas SDM yang memadai, maka seseorang dapat mengabdi dengan menjadi Pegawai yang baik. Selain dikarenakan, maka kinerja dapat pula ditunjukkan oleh pengalaman kerja. Artinya, jika seseorang telah lama berada dalam suatu bidang pekerjaan tertentu dalam pengalaman kerja yang membuat pegawai merasa nyaman, maka dapat dipastikan bahwa ia akan menunjukkan kinerja yang baik. Hal ini sesungguhnya disebabkan karena lamanya seseorang bekerja, sudah tentu ia akan memiliki penguasaan terhadap pekerjaan yang baik pula. Dalam teori sumber daya manusia dinyatakan bahwa terdapat kecenderungan kemampuan 
bekerja yang tinggi bagi seseorang yang memiliki tingkat pendidikan tinggi, demikian pula halnya dengan pemahaman atau pengetahuan terhadap pekerjaan.

Hal ini dinyatakan oleh Pakar sumber daya manusia, Alex Nitisemidjo (2001; 15) menyatakan bahwa terdapat kecenderungan bahwa tingkat pendidikan serta pengalaman kerja berhubungan dengan kemampuan bekerja seseorang.

Selain itu, Manullang (1999; 1) menjelaskan bahwa kinerja adalah spesifikasi dari pengetahuan (pendidikan), (pengalaman) dan sikap yang dimiliki seseorang serta penerapannya dalam bekerja.Kedua pendapat di atas menyimpulkan bahwa sesungguhnya kinerja seseorang memiliki hubungan dengan pendidikan, dan pengalaman kerja.

Bekal pendidikan adalah bekal yang mampu menjadikan seorang manusia memiliki makna dalam kehidupan. Dengan adanya pendidikan, seseorang mampu pula meningkatkan harkat dan martabatnya melalui peningkatan kesejahteraan dengan cara bekerja. Dari kerja itulah ia memperoleh reward yang dapat dijadikan sebagai alat peningkatan kesejahteraan hidupnya. Pendidikan yang baik akan memberikan pengetahuan dan wawasan bagi seseorang. Demikian pula halnya dengan pekerjaan. Menurut (Salim, 2020) Pendidikan yang sesuai akan memberikan dampak positip terhadap kinerja seseorang, dimana secara umum pendidikan yang tinggi akan dapat memberikan kinerja yang baik pula.

Menurut (Azis \& Alaydrus, 2021) Selain pendidikan, pengalaman kerja juga mampu memberikan kinerja lebih baik bagi seseorang yang memiliki pengalaman kerja yang tinggi. Semakin lama waktu atau semakin besar pengalaman seseorang dalam bidang pekerjaannya akan memberikan pengetahuan mengenai pekerjaannya secara baik, dan hal tersebut mempengaruhi kinerja seseorang, dengan kata lain semakin tinggi pengalaman kerja seseorang semakin tinggi pula kinerjanya. Pegawai yang mengabdi pada Biro Perlengkapan Umum Kantor Bupati Sigi, sesungguhnya dituntut untuk memiliki kemampuan dalam bekerja, mengingat peran dan fungsi kantor Biro Perlengkapan Umum Kantor Bupati Sigi sebagai perpanjangan tangan pemerintah Kabupaten.

Hal tersebut di atas yang mendasari peneliti untuk melakukan suatu penelitian mengenai pengaruh pendidikan dan pengalaman kerja terhadap kinerja Pegawai Biro Perlengkapan Umum Kantor Bupati Sigi.

\section{Rumusan Masalah}

Berdasarkan uraian latar belakang penelitian, maka masalah diidentifikasi sebagai berikut:

1. Apakah pendidikan dan pengalaman kerja secara serempak berpengaruh signifikan terhadap kinerja pegawai Biro Perlengkapan Umum Kantor Bupati Sigi?

2. Apakah pendidikan berpengaruh signifikan terhadap kinerja pegawai Biro Perlengkapan Umum Kantor Bupati Sigi?

3. Apakah pengalaman kerja berpengaruh signifikan terhadap kinerja pegawai Biro Perlengkapan Umum Kantor Bupati Sigi?

\section{Tujuan Penelitian}

Tujuan penelitian ini adalah untuk mengetahui: 
1. Pengaruh pendidikan dan pengalaman kerja secara serempak terhadap kinerja pegawai Biro Perlengkapan Umum Kantor Bupati Sigi

2. Pengaruh pendidikan terhadap kinerja pegawai Biro Perlengkapan Umum Kantor Bupati Sigi

3. Pengaruh pengalaman kerja terhadap kinerja pegawai Biro Perlengkapan Umum Kantor Bupati Sigi

\section{Kegunaan Penelitian}

Hasil penelitian ini diharapkan memberikan kegunaan sebagai berikut:

1. Kegunaan teoritis

Secara teoritis penelitian ini diharapkan dapat memberikan sumbangan dalam pengembangan ilmu ekonomi manajemen sumber daya manusia khususnya menyangkut faktor yang mempengaruhi kinerja pegawai.

2. Kegunaan praktis

Secara praktis hasil penelitian ini diharapkan bermanfaat untuk menentukan kebijakan serta pengambilan keputusan dalam pengelolaan sumber daya manusia terutama dalam hal pengembangan sikap dan perilaku pegawai.

\section{Metode Penelitian}

\section{Jenis Penelitian}

Penelitian ini bersifat penelitian lapangan (field research) yaitu penelitian yang berusaha menjelaskan hubungan kausal antara variabel-variabel yang dijadikan tolak ukur dalam penelitian ini dan untuk menguji hipotesis yang ada (Rangkuti; 1997; 83). Pengujian hipotesis ini dimaksudkan untuk mengetahui pengaruh pendidikan dan pengalaman kerja terhadap kinerja pegawai Biro Perlengkapan Umum Kantor Bupati Sigi.

\section{Metode Pengumpulan data}

Guna memperoleh data primer dan sekunder, peneliti menggunakan beberapa metode pengumpulan data, yaitu:

a. Observasi, dilakukan dengan mendatangi langsung pada objek penelitian guna melihat secara langsung kinerja serta pelayanan yang diberikan kepada publik oleh pegawai Biro Perlengkapan Umum Kantor Bupati Sigi. Data yang diperoleh adalah data deskriptif menyangkut kondisi kepegawaian di Biro Perlengkapan Umum Kantor Bupati Sigi.

b. Wawancara, dilakukan dengan mengajukan sejumlah pertanyaan tidak tertulis kepada narasumber yang dianggap memahami penelitian ini. Data yang diperoleh adalah data tanggapan menyangkut kinerja pegawai Biro Perlengkapan Umum Kantor Bupati Sigi

c. Kuesioner, dilakukan dengan pengumpulan tanggapan responden melalui kuesioner yang diedarkan. Adapun bentuk kuesioner yang diedarkan adalah tertutup, artinya responden memilih salah satu jawaban yang dianggap paling benar menurut responden. Data yang diperoleh adalah data tanggapan mengenai pendidikan, dan pengalaman kerja terhadap kinerja Pegawai pada Biro Perlengkapan Umum Kantor Bupati Sigi

d. Dokumentasi, dilakukan dengan mengumpulkan data-data pendukung, baik berupa angka maupun grafik mengenai profil Biro Perlengkapan Umum Kantor Bupati 
Sigi. Data yang diperoleh adalah data jumlah pegawai, keadaan pegawai, dan Tupoksi Biro Perlengkapan Umum Kantor Bupati Sigi.

\section{Populasi dan Sampel Populasi}

Populasi dalam penelitian ini adalah jumlah seluruh pegawai Biro Perlengkapan Umum Kantor Bupati Sigi, baik itu pegawai berstatus PNS maupun CPNS, dengan rincian sebagai berikut:
a. Pegawai PNS
60 orang
b. Pegawai CPNS
93 orang

Jumlah seluruh pegawai Biro Perlengkapan Umum Kantor Bupati Sigi sebanyak 153 orang.

\section{Sampel}

Penentuan besarnya sampel dilakukan dengan menggunakan formulasi rumus Slovin yang dikemukakan oleh Taro Yamane (dalam Ridwan, 2005; 65) sebagai berikut:

$$
\mathrm{n}=\frac{\mathrm{N}}{\mathrm{N} . \mathrm{d}^{2}+1}
$$

Di mana:

$$
\begin{array}{ll}
\mathrm{n} & =\text { Jumlah sampel } \\
\mathrm{N} & =\text { Jumlah populasi } \\
\mathrm{d}^{2} & =\text { presisi yang ditetapkan }
\end{array}
$$

Berdasarkan rumus tersebut, dengan besaran presisi sebesar 10\%, maka jumlah sampel penelitian adalah sebagai berikut:

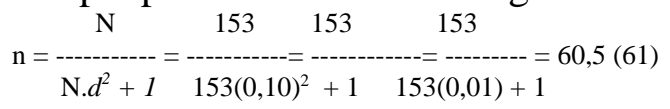

Dengan demikian, dari sebanyak 153 populasi yang ada, diambil sebanyak 61 responden dengan menggunakan teknik proporsional sampling.

\section{Metode Analisis}

\section{Uji Instrumen Penelitian}

Uji kesahihan dimaksudkan untuk mengetahui kemampuan setiap butir instrumen dalam menjelaskan variabelnya masing-masing. Uji kesahihan instrumen dapat dilakukan dengan mengkorelasikan skor tiap butir dengan skor total melalui teknik korelasi produc moment atau disebut korelasi Person. Pengujian korelasi Person dilakukan melalui bantuan program komputer SPSS versi 19. Kaidah pengambilan keputusan yaitu:

a. Jika nilai probabilita atau dalam output komputer disebut Sig.2 tailed lebih kecil dari taraf signifikansi $(\alpha)$ 0,05 maka butir tersebut berstatus sahih atau tepat dalam menjelaskan variabelnya.

b. Jika nilai probabilita (Sig.2 tailed) lebih besar dari taraf signifikansi $(\alpha)$ 0,05 maka butir tersebut berstatus tidak sahih atau tidak tepat dalam menjelaskan variabelnya sehingga butir tersebut dinyatakan gugur sehingga tidak digunakan dalam penelitian selanjutnya.

Untuk melakukan teknik korelasi Person digunakan bantuan program aplikasi komputer. Kriteria pengujian menggunakan perbandingan antara nilai probabilita (Sig.1 tailed) dengan taraf

\begin{tabular}{|c|c|c|c|c|}
\hline \multirow{2}{*}{$\begin{array}{l}\text { Butir } \\
\text { Instrumen }\end{array}$} & \multirow[b]{2}{*}{ Probabiliti } & \multirow[b]{2}{*}{ (a) } & \multicolumn{2}{|c|}{ Kesahihan Butir } \\
\hline & & & Sahih & Gugur \\
\hline Butir.1 & 0,000 & \multirow{5}{*}{0,05} & Sahih & - \\
\hline Butir .2 & 0,000 & & Sahih & - \\
\hline Butir .3 & 0,000 & & Sahih & - \\
\hline Butir .4 & 0,000 & & Sahih & - \\
\hline Butir & 0,017 & & Sahih & - \\
\hline
\end{tabular}
signifikansi $(\alpha)$ 0,05. Berdasarkan olahan data disajikan hasil pengujian kesahihan butir pada variabel pendidikan sebagai berikut:

Pada variabel pendidikan menunjukan nilai probabilita semua butir lebih kecil dari taraf signifikansi 0,05 sehingga 
membuktikan seluruh butir variabel berstatus sahih. Selanjutnya disajikan hasil uji variabel pengalaman kerja, sebagai berikut:

\begin{tabular}{|c|c|c|c|c|}
\hline \multirow{2}{*}{$\begin{array}{c}\text { Butir } \\
\text { Instrumen }\end{array}$} & \multirow[b]{2}{*}{ Probabiliti } & \multirow[b]{2}{*}{ (a) } & \multicolumn{2}{|c|}{ Kesahihan Butir } \\
\hline & & & Sahih & Gugur \\
\hline Butir .1 & 0,000 & \multirow{5}{*}{0,05} & Sahih & - \\
\hline Butir .2 & 0,000 & & Sahih & - \\
\hline Butir .3 & 0,000 & & Sahih & - \\
\hline Butir .4 & 0,000 & & Sahih & - \\
\hline Butir .5 & 0,001 & & Sahih & - \\
\hline
\end{tabular}

Pada variabel Pengalaman kerja menunjukan nilai probabilita semua butir lebih kecil dari taraf signifikansi 0,05 sehingga membuktikan seluruh butir variabel berstatus sahih.

Selanjutnya disajikan hasil uji variabel kinerja, sebagai berikut:

\begin{tabular}{|c|c|c|c|c|}
\hline \multirow{2}{*}{$\begin{array}{c}\text { Butir } \\
\text { Instrumen }\end{array}$} & \multirow[b]{2}{*}{ Probabiliti } & \multirow[b]{2}{*}{ (a) } & \multicolumn{2}{|c|}{ Kesahihan Butir } \\
\hline & & & Sahih & Gugur \\
\hline Butir.1 & 0,000 & \multirow{7}{*}{0,05} & Sahih & - \\
\hline Butir .2 & 0,001 & & Sahih & - \\
\hline Butir .3 & 0,000 & & Sahih & - \\
\hline Butir .4 & 0,013 & & Sahih & - \\
\hline Butir .5 & 0,000 & & Sahih & - \\
\hline Butir .6 & 0,017 & & Sahih & - \\
\hline Butir .7 & 0,003 & & Sahih & - \\
\hline
\end{tabular}

Pada variabel kinerja menunjukan nilai probabilita semua butir lebih kecil dari taraf signifikansi 0,05 sehingga membuktikan seluruh butir variabel berstatus sahih.

Uji keandalan dimaksudkan untuk mengetahui keandalan atau konsistensi dari instrumen dalam memberikan hasil pengukuran. Jika hasil pengukuran sama nilainya dalam pengukuran yang berulang kali maka instrumen tersebut dinyatakan andal sehingga cukup baik digunakan sebagai instrumen pengukuran.

Pengujian reliabilitas dalam penelitian ini menggunakan teknik Alpha Cronbach yaitu dengan melihat nilai Alpha Cronbach yang dihasilkan dari perhitungan melalui output SPSS. Batas minimal yang dapat digunakan untuk menilai tingkat realibilitas yang dapat diterima adalah 0.60 (Zethami Berry A, Pasuraman; 1996).

Hasil perhitungan rumus alpha (cronbach alpha) menunjukkan semua variabel baik secara individu maupun secara keseluruhan adalah reliabel karena tidak satupun variabel tersebut yang memiliki nilai di bawah 0,60 , seperti terlihat pada tabel berikut:

\begin{tabular}{|c|c|c|}
\hline Variabel & $\begin{array}{c}\text { Cronbach } \\
\text { Alpha }\end{array}$ & Keterangan \\
\hline Kinerja & 0,995 & Reliabel \\
Butir-1 & 0.887 & Reliabel \\
Butir-2 & 0.855 & Reliabel \\
Butir-3 & 0.828 & Reliabel \\
Butir-4 & 0.600 & Reliabel \\
Butir-5 & 0.928 & Reliabel \\
Butir-6 & 0.894 & Reliabel \\
Butir-7 & 0.870 & Reliabel \\
\hline Pendidikan & 0,755 & Reliabel \\
Butir-1 & 0.705 & Reliabel \\
Butir-2 & 0.735 & Reliabel \\
Butir-3 & 0.673 & Reliabel \\
Butir-4 & 0.673 & Reliabel \\
Butir-5 & 0.850 & Reliabel \\
\hline Pengalaman Kerja & 0.886 & Reliabel \\
Butir-1 & 0.782 & Reliabel \\
Butir-2 & 0.765 & Reliabel \\
Butir-3 & 0.661 & Reliabel \\
Butir-4 & 0.793 & Reliabel \\
Butir-5 & 0.812 & Reliabel \\
\hline
\end{tabular}

\section{Uji Regresi Linier Berganda}

Analisis kuantitatif dalam penelitian ini digunakan untuk mengolah data yang berbentuk angka melalui formulasi statistik yaitu analisis regresi linier Berganda. Persamaan regresi linier Bergandaanda menurut Rangkuti (1997;165-166) sebagai berikut:

$$
\mathrm{Y}=\mathrm{b}_{0}+\mathrm{b}_{1} \mathrm{X}_{1}+\ldots \ldots \ldots \ldots+\mathrm{b}_{\mathrm{n}} \mathrm{X}_{\mathrm{nl}}+\mathrm{e}
$$

Di mana:

$\mathrm{Y} \quad=$ Variabel Dependent

$\mathrm{X}_{\mathrm{n}} \quad=$ Variabel Independent

$\mathrm{b}_{0} \quad=$ Konstanta

$\mathrm{b}_{\mathrm{n}} \quad=$ Koefisien regresi

e $\quad=$ Standar Error

Dalam kasus ini persamaan menjadi: 


$$
\mathrm{Y}=\mathrm{b}_{0}+\mathrm{b}_{1} \mathrm{X}_{1}+\mathrm{b}_{2} \mathrm{X}_{2}+e
$$

Di mana:

$\mathrm{Y} \quad=$ Kinerja

$\mathrm{X}_{1} \quad=$ Pendidikan

$\mathrm{X}_{2} \quad=$ Pengalaman Kerja

$\mathrm{b}_{0} \quad=$ Konstanta

$\mathrm{b}_{1}-\mathrm{b}_{3}=$ Koefisien regresi

e $\quad=$ Standar Error

Kriteria pengambilan keputusan uji serempak didasarkan atas pedoman Santoso yaitu perbandingan antara nilai probabilita $\left(\mathrm{F}_{\mathrm{Sig}}\right)$ dengan taraf signifikansi 0,05 (Santoso, 2001; 204):

a. Jika nilai $\mathrm{F}_{\mathrm{Sig}}<\alpha \quad 0,05$ maka terbukti secara serempak pendidikan dan pengalaman kerja berpengaruh signifikan terhadap kinerja pegawai Biro Perlengkapan Umum Kantor Bupati Sigi, atau dengan kata lain keputusan uji hipotesis menerima $\mathrm{H}_{1}$ dan menolak $\mathrm{H}_{0}$.

b. Jika nilai $\mathrm{F}_{\mathrm{Sig}}>\alpha 0,05$ maka terbukti secara serempak pendidikan dan pengalaman kerja tidak berpengaruh signifikan terhadap kinerja pegawai Biro Perlengkapan Umum Kantor Bupati Sigi, atau dengan kata lain keputusan uji hipotesis menerima $\mathrm{H}_{0}$ dan menolak $\mathrm{H}_{1}$

Menguji signifikansi parsial dilakukan dengan membandingkan nilai-nilai probabilita koefisien regresi parsial $\left(\mathrm{t}_{\mathrm{sig}}\right)$ dengan taraf signifikansi 0,05 (Santoso, 2001; 203), melalui kriteria pengambilan keputusan sebagai berikut:

a. Jika nilai $\mathrm{t}_{\mathrm{Sig}}<\alpha \quad 0,05$ maka terbukti secara parsial variabel pendidikan dan pengalaman kerja berpengaruh signifikan terhadap kinerja pegawai Biro Perlengkapan Umum Kantor Bupati Sigi.

b. Jika nilai $\mathrm{t} S \mathrm{Sig}>\alpha 0,05$ maka terbukti secara parsial variabel pendidikan dan pengalaman kerja tidak berpengaruh signifikan terhadap kinerja pegawai Biro Perlengkapan Umum Kantor Bupati Sigi.

Dalam melakukan teknik kuantitatif, penulis menggunakan bantuan program komputer SPSS release 19. Dalam hal ini penulis menggunakan pedoman dari Santoso (2001).

\section{Hasil dan Pembahasan \\ Hasil}

Regresi Linear Berganda merupakan salah satu alat statistik Parametrik dengan fungsi menganalisis dan menerangkan keterkaitan antara dua atau lebih faktor penelitian yang berbeda nama, melalui pengamatan pada beberapa hasil observasi (pengamatan) di berbagai bidang kegiatan. Berkaitan dengan penelitian ini alat analisis Statistik Parametrik Regresi Linear Berganda yang digunakan untuk mengetahui pengaruh variabel independen $(\mathrm{X})$ terhadap variabel dependen (Y). Dalam konteks penelitian ini Regresi Linear Berganda digunakan untuk mengukur pengaruh pendidikan, , dan pengalaman kerja terhadap kinerja Pegawai Biro Perlengkapan Umum Kantor Bupati Sigi.

Sesuai hasil analisis Regresi Linear Berganda dengan menggunakan bantuan komputer SPSS For Wind Release 19,0 diperoleh hasil-hasil penelitian dari 101 orang responden dengan dugaan pengaruh variabel pendidikan, dan pengalaman kerja terhadap Kinerja Pegawai Biro Perlengkapan Umum Kantor Bupati Sigi dapat diketahui hasil perhitungan sebagai berikut: 
Hasil Perhitungan Regresi Berganda

\begin{tabular}{|l|c|c|c|c|}
\hline \multicolumn{5}{|c|}{ Dependen Variabel Y = Kineria } \\
\hline Variabel & beta & $\begin{array}{c}\text { Stand } \\
\text { ar } \\
\text { Error }\end{array}$ & $\mathbf{t}$ & Sig \\
\hline Konstanta (a) & 3.782 & 0.419 & 9.027 & 0.000 \\
\hline Pendidikan & 0.026 & 0.063 & 0.413 & 0.681 \\
\hline Pengalaman ker & 0.211 & 0.096 & 2.206 & 0.031 \\
\hline $\begin{array}{l}\mathrm{R}=0,723 \\
\text { R-Square }=0,523\end{array}$ F-Statistik $=31.375$ \\
Sig. F $=0,000$ \\
\hline
\end{tabular}

Model regresi yang diperoleh dari tabel di atas adalah:

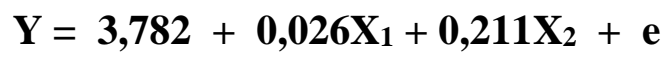

Persamaan di atas menunjukkan, variable independen yang dianalisa berupa variabel $\left(\mathrm{X}_{1}, \mathrm{X}_{2}\right.$, dan $\left.\mathrm{X}_{3}\right)$ memberi pengaruh terhadap variable independen (Y) model analisis regresi Kinerja Pegawai Biro Perlengkapan Umum Kantor Bupati Sigi dapat dianalisis sebagai berikut:

\section{a. Pengaruh pendidikan, dan pengalaman kerja, secara serempak terhadap kinerja Pegawai Biro Perlengkapan Umum Kantor Bupati Sigi}

Uji serempak adalah sebuah pengujian untuk mengetahui apakah variabel independen (X) yang diteliti memilki pengaruh terhadap variabel dependen $(Y)$ berarti semua variabel bebasnya, yakni Pendidikan, dan pengalaman kerja dengan variabel tidak bebasnya yaitu Kinerja Pegawai Biro Perlengkapan Umum Kantor Bupati Sigi yakni:

Dari persamaan di atas dapat dijelaskan:

1) Untuk nilai constanta sebesar 3.782 berarti Kinerja Pegawai Biro Perlengkapan Umum Kantor Bupati Sigi sebelum adanya variabel independen adalah sebesar 3.782.

2) Untuk nilai dengan koefisien regresi masing-masing sebesar 0,026 atau $2,6 \%$ untuk pendidikan, dan sebesar
0.211 atau $21,1 \%$ untuk pengalaman kerja, berarti terjadi hubungan yang positif antara kedua variabel dengan kinerja Pegawai Biro Perlengkapan Umum Kantor Bupati Sigi.

Sedangkan dari uji determinasi (kehandalan model) memperlihatkan nilai $\mathrm{R}^{2}$ Square $=0,523$ atau $=52,3 \%$. Hal ini berarti bahwa sebesar $52,3 \%$ variabel tidak bebas dipengaruhi oleh ketiga variabel bebas, selebihnya variabel tidak bebas dipengaruhi oleh variabel lain yang tidak diteliti.

Selanjutnya berdasarkan Tabel di atas dari hasil perhitungan diperoleh F-hitung $=31.375$ pada taraf nyata $\alpha=0,05$ atau $\mathrm{P}$ $<0,05$. Dari tabel tersebut menunjukkan bahwa nilai signifikansi Probabilitas = 0,000. Dengan demikian dapat dinyatakan bahwa secara bersama-sama variabel bebas mempunyai pengaruh yang signifikan terhadap variabel tidak bebasnya.

Dengan demikian maka hipotesis pertama yang menyatakan bahwa: pendidikan, , dan pengalaman kerja, berpengaruh positip dan signifikan terhadap kinerja Pegawai Biro Perlengkapan Umum Kantor Bupati Sigi berdasarkan, terbukti kebenarannya.

\section{b. Pengaruh Pendidikan terhadap kinerja Pegawai Biro Perlengkapan Umum Kantor Bupati Sigi}

Untuk variabel pendidikan, hasil perhitungannya menunjukkan bahwa nilai koefisien regresi sebesar 0,026 , sementara tingkat signifikasi sebesar 0,681. Dengan demikian nilai $\mathrm{P}>0,05$ pada taraf kepercayaan 95\%. Sehingga dapat dinyatakan bahwa variabel pendidikan mempunyai pengaruh yang tidak signifikan terhadap Kinerja Pegawai Biro Perlengkapan Umum Kantor Bupati Sigi. 
Dengan demikian maka hipotesis kedua yang menyatakan bahwa: pendidikan berpengaruh signifikan terhadap kinerja Pegawai Biro Perlengkapan Umum Kantor Bupati Sigi, ditolak.

\section{c. Pengaruh pengalaman kerja terhadap kinerja Pegawai Biro Perlengkapan Umum Kantor Bupati Sigi}

Untuk variabel pengalaman kerja, perhitungannya menunjukkan bahwa nilai koefisien regresi sebesar 0,211 , sementara tingkat signifikasi sebesar 0,031. Dengan demikian nilai $\mathrm{P}<0,05$ pada taraf kepercayaan 95\%. Sehingga dapat dinyatakan bahwa variabel Pengalaman kerja mempunyai pengaruh yang signifikan terhadap Kinerja Pegawai Biro Perlengkapan Umum Kantor Bupati Sigi.

Dengan demikian maka hipotesis keempat yang menyatakan bahwa Pengalaman kerja berpengaruh positip dan signifikan terhadap kinerja Pegawai Biro Perlengkapan Umum Kantor Bupati Sigi, juga tidak ditolak

\section{d. Variabel dominan berpengaruh terhadap kinerja Pegawai Biro Perlengkapan Umum Kantor Bupati Sigi}

Berdasarkan hasil yang terurai secara parsial, maka ditemukan bahwa variabel yang cenderung dominan berpengaruh terhadap kinerja Pegawai Biro Perlengkapan Umum Kantor Bupati Sigi adalah variabel pengalaman kerja. Nilai variabel pengalaman kerja, khususnya pada nilai koefisien regresi memiliki nilai terbesar dibanding nilai yang sama untuk variabel pendidikan.

\section{PEMBAHASAN}

Pengaruh pendidikan, dan pengalaman kerja secara serempak berpengaruh positip dan signifikan terhadap kinerja Pegawai Biro Perlengkapan Umum Kantor Bupati Sigi

Hasil penelitian membuktikan bahwa dalam penelitian ini seluruh faktor independen berpengaruh positif terhadap kinerja Pegawai Biro Perlengkapan Umum Kantor Bupati Sigi. Artinya jika ketiga variabel tersebut diperlakukan dalam waktu yang bersamaan, maka hal tersebut menimbulkan peningkatan kinerja pegawai. Pendidikan memberikan bekal pengetahuan bagi pegawai, sementara pengalaman kerja memberikan bekal secara teknis dalam melaksanakan pekerjaan. Artinya jika, pendidikan dan pengalaman kerja yang dimiliki pegawai, maka dapat dipastikan bahwa kinerja pegawai juga tinggi.

\section{Pengaruh Pendidikan terhadap kinerja Pegawai Biro Perlengkapan Umum Kantor Bupati Sigi}

Hasil penelitian ini menunjukkan bahwa kontribusi variabel pendidikan terhadap kinerja pegawai Biro Perlengkapan Umum Kantor Bupati Sigi sebesar 0,026, yang berarti bahwa pendidikan mempengaruhi kinerja pegawai Biro Perlengkapan Umum Kantor Bupati Sigi hanya sebesar 0,026. Pengaruh yang diberikan sesungguhnya memang relatif kecil. Hal ini disebabkan bahwa di Biro Perlengkapan Umum Kantor Bupati Sigi, unsur pendidikan tidaklah menjadi penentu terhadap kinerja pegawai, sebab banyak pegawai di Biro Perlengkapan Umum Kantor Bupati Sigi di tempatkan tidak sesuai dengan latar belakang pendidikan formal yang dimiliki. 
Pengaruh Pengalaman kerja terhadap kinerja Pegawai Biro Perlengkapan Umum Kantor Bupati Sigi

Menurut (Umar A, 2019) Seorang yang memiliki pengalaman kerja yang tinggi dapat lebih berkinerja dalam bekerja dibanding pegawai yang memiliki pendidikan tinggi tetapi pengalaman kerja rendah.

Hal ini dibuktikan dalam penelitian ini, dimana pengalaman kerja lebih dominan pengaruhnya terhadap kinerja pegawai Biro Perlengkapan Umum Kantor Bupati Sigi dibanding pendidikan. Kontribusi yang diberikan oleh variabel pengalaman kerja terhadap kinerja sebesar 0,211.

Seorang pegawai yang telah berpengalaman, dengan sendirinya memiliki keterampilan dalam menyelesaikan pekerjaan. Banyak pegawai di Biro Perlengkapan Umum Kantor Bupati Sigi adalah pegawai dari bidang lain bahkan ada dari instansi lain sebelum mengabdi di Biro Perlengkapan Umum Kantor Bupati Sigi.

\section{Kesimpulan}

a. Secara serempak pendidikan, dan pengalaman kerja berpengaruh signifikan terhadap kinerja Pegawai Biro Perlengkapan Umum Kantor Bupati Sigi, hipotesis pertama terbukti.

b. Pendidikan berpengaruh tidak signifikan terhadap kinerja Pegawai Biro Perlengkapan Umum Kantor Bupati Sigi, hipotesis kedua terbukti.

c. Pengalaman kerja berpengaruh signifikan terhadap kinerja Pegawai Biro Perlengkapan Umum Kantor Bupati Sigi, hipotesis ketiga terbukti.

\section{Saran}

a. Kepada para pegawai Biro Perlengkapan Umum Kantor Bupati
Sigi, agar tetap mengutamakan kinerja dalam melaksanakan pekerjaan. yang mendukung dapat dijadikan patokan untuk bekerja secara baik dan secara benar.

b. Kepada Kepala Biro, agar selalu memotivasi pegawai untuk memiliki pendidikan formal, karena walaupun pendidikan dalam penelitian ini memiliki pengaruh yang kecil, namun untuk masa depan, pendidikan adalah hal yang sangat penting

\section{DAFTAR RUJUKAN}

Abadiyah, A. K. (2021). Pengaruh Fasilitas Kerja, Kemampuan Dan Disiplin Kerja Terhadap Kinerja Pegawai Pada Kantor Kecamatan Tinombo Kabupaten Parigi Moutong. Jurnal Ekonomi Trend, 7(2), 19-29.

https://doi.org/10.31970/trend.v7i2. 177

As'ad Moh, 2000, Psikologi Industri, Edisi Revisi, Liberty, Yogyakarta

Asri Marwan dan Dwi Sulistyo Budi Awig, 1986. Pengelolaan Karyawan. BPFE-UGM, Yogyakarta

Azis, A., \& Alaydrus, A. (2021). PENGARUH MOTIVASI, DISIPLIN, DAN LINGKUNGANKERJA TERHADAP KINERJA PEGAWAI DINAS PENDIDIKAN KOTA PALU. Jurnal Ekonomi Trend, 9(1), 23-34. https://doi.org/10.31970/trend.v9i1. 204 
Dessler, Gregor, 1997. Human Resources. Terjemahan FX. Lamarto, Sinar Agung, Jakarta

Duncan Hill, 1987. Pengembangan Manusia dan Karyawan Swasta. Mandar Madju, Bandung

Flippo, Edwin S, 1994. Organisasi dan Manajemen; Perilaku, Struktur, Proses. Erlangga, Jakarta

Gibson, 1994. Manajemen Sumber Daya Manusia. Mandar Madju, Bandung

Halsey and Blanchord, 1992. Human dan Employmanet. Terjemahan Anas Setyaningsih. BPFE-UGM Yogyakarta

Luthans, Lussler, 2003, Human Relation in organization, skill build Approach, Irwin USA

Maslow, Abraham H, 1984. Pendidikan, Kepribadian, Teori Pendidikan Dengan Pendekatan Hirarki Kebutuhan Manusia. Pustaka Binaman Pressindo, Bandung

Mathis dan Lackson, 2002, Human Relation in Organization, Skill Bull Aprocoes Irwin USA.

Mondy dan Noe, 2005, Human Relation in organization, skill build Approach, Irwin USA.

Ridwan, 2005. Metode Penelitian Sosial. Ghalia Indonesia, Jakarta

Salim, F. U. (2020). PENGARUH ADVERSITY QUOTIENT DAN KOMPETENSI TERHADAP KINERJA KARYAWAN PT.
ASKES (PERSERO) PALU. Jurnal Ekonomi Trend, 8(1), 26-34. https://doi.org/10.31970/trend.v8i1. 183

Santoso, Singgih, 2001, SPSS Statistik Parametrik, Lembaga Penerbit PT. Elex Media Komputindo, Jakarta

Umar A, M. (2019). STRATEGI PEMASARAN DALAM UPAYA PENINGKATKAN VOLUME PENJUALAN PERUSAHAAN COMFORTA PALU. Jurnal Ekonomi Trend, 7(1), 27-40. https://doi.org/10.31970/trend.v7i1. 171 